\title{
Study on Knowledge, Adoption and Constraints Faced by Farmers about Soil Health Card based Fertilizer Application in Neemuch District, India
}

\author{
P.S. Naruka, Shilpi Verma*, C.P. Pachauri, S.S. Sarangdevot, \\ Shilpi Kerketta, S.S. Bhadauria and J.P. Singh \\ Krishi Vigyan Kendra, Neemuch, India \\ *Corresponding author
}

\section{A B S T R A C T}

\begin{tabular}{|l|}
\hline K e y w o r d s \\
$\begin{array}{l}\text { Adoption, Knowledge, } \\
\text { Constraints, Soil } \\
\text { health cards and Soil } \\
\text { testing. }\end{array}$ \\
\hline Article Info \\
\hline $\begin{array}{l}\text { Accepted: } \\
\text { 15 June 2018 } \\
\text { Available Online: } \\
\text { 10 July } 2018\end{array}$ \\
\hline
\end{tabular}

Keywords

nowledge,

\begin{abstract}
Indian government launched soil health card programme in the year 2015-2016 in order to increase agricultural production and sustain soil health. Since inception of soil health card programme, a huge number of soil health cards have been given to the farmers. In order to know the knowledge, adoption and constraints of soil health card, the present study was carried out. The farmers who were issued soil health card were comparatively more aware about various soil health card aspects like major nutrients (N, P \& K), soil pH and Soil EC and micronutrients as compared to farmers without soil health card. Majority of the farmers had medium knowledge level towards soil health card. Major constraints faced by the farmers in adoption according to soil health card were difficulty in having knowledge about the importance of micronutrients, the prices of fertilizers being too high and on nonavailability of organic manure.
\end{abstract}

\section{Introduction}

Soil is one of the elements required for farming as it provides nutrients to the plant. Healthy soil contain all the elements for growth and development of crop or the soil deprived from one or more nutrient either reduce the production or degraded quality of crops. Therefore, proportion and quantity of macro and micro nutrients altogether refer to the soil health. As far as agriculture production is concerned, soil health play vital role in ensuring sustainable production with optimizing the utilization of fertilizer and reducing its waste (Patel et al, 2017). Most of the farmers are using continuously larger quantities of chemical fertilizers to increase production without knowing the fertility status of the soils of their fields (Srivastava and Pandey, 1999). Soil Testing is well recognized as a sound scientific tool to assess inherent power of soil to supply plant nutrients. The benefits of soil testing have been established through scientific research, extensive field demonstrations and on the basis of actual fertilizer use by the farmers on soil test based fertilizer use recommendations. Neufeld et al (2006) stated that soil testing is the only necessary and available tool for determining the amount of soil nutrients. To avoid 
deterioration of soil in long run and visualizing the importance of balance nutrient in crop production, government commence soil health card programme. The soil health card (SHC) provides soil health data to get appropriate guidance to the farmers for the efficient use of fertilizer to cultivate crops based on soil health analysis. The SHC is a simple document, which contains useful data on soil based on chemical analysis of the soil to describe soil health in terms of its nutrient availability and its physical and chemical properties. The soil health card is made available online also for the farmers. Soil health card can be used to optimize the use of fertilizer in the integrated nutrient management (INM) system. The soil health card programme brings together the scientific community in the field of agriculture, the information repository of latest tool, techniques and cropping practices, the farmers and the Government for the economics upliftment of the people at large. Since, change in knowledge preceded acceptance and application of an innovation, it is therefore, always important to find out the factor responsible for positive or negative disposition associated with farmer toward the usefulness and application of soil health card programme. To understand the feelings of the farmers against this system, there was an urgent need to study the degree of positive or negative disposition associated with farmer towards the usefulness and application of soil health card.

Hence, present study entitled Knowledge, adoption and constraints faced by farmers about Soil health card based fertilizer Application in Neemuch District was planned with following specific objectives-

1. To study the knowledge level of the farmers towards soil health card based fertiliser application

2. To study the adoption level of the farmers towards soil health card based fertiliser application
3. To study the constraints faced by the farmers towards soil health card based fertiliser application

\section{Materials and Methods}

The present study was conducted in Neemuch district (M.P). This district consists of 3 blocks. From which one block viz., neemuch was selected purposively looking to the number of respondent having soil health card. Five villages having more number of respondents from the block were selected. A comprehensive list of all the respondents having SHC was obtained from the respective villages. Thus, ten respondents from each village comprising of total no. of respondents to be 50 were selected at random sample for the study. The data were collected through pre-tested interview schedule. The data were tabulated and analyzed in light of the objectives to draw the meaningful conclusion. The statistical tools used for the analysis of the data were percentage, mean and standard deviation.

\section{Results and Discussion}

\section{Knowledge among farmers about Soil health card}

Data in table 1 shows that maximum no. of respondents had medium knowledge score that is $58 \%$ followed by respondents with low knowledge score $(26 \%)$ and only 16 percent respondents had high knowledge score about soil health card. The findings are supported by Bhatt et al, 2010. Agbamu's (1993) findings stated that farmers' knowledge of technology made contribution to its adoption. They found the technology satisfactory and important with respect to lower the input cost, benefit of soil testing and use of soil health card in their farming operation. 
Table.1 Knowledge among farmers about Soil Health Card

\begin{tabular}{|c|l|c|c|}
\hline S.No & \multicolumn{1}{|c|}{ Item } & Percentage & Rank \\
\hline $\mathbf{1}$ & Low Knowledge Level (Score upto 13.85) & 26 & II \\
\hline $\mathbf{2}$ & Medium Knowledge Level (Score From 13.86 to 18.64) & 58 & I \\
\hline $\mathbf{3}$ & High Knowledge Level (Score above 18.64) & 16 & III \\
\hline
\end{tabular}

Table.2 Adoption among farmers according Soil Health Card based fertilizer application

\begin{tabular}{|c|c|c|c|c|}
\hline S.No & Item & $\begin{array}{l}\text { No. of farmers finding soil } \\
\text { nutrient deficient in SHC }\end{array}$ & $\begin{array}{c}\text { No. of Farmers } \\
\text { adopted acc. To SHC }\end{array}$ & $\begin{array}{c}\text { Adoption } \\
\text { Percent }\end{array}$ \\
\hline \multicolumn{5}{|c|}{ Analysis of soil nutrients } \\
\hline 1 & Soil pH & 12 & 10 & 83.33 \\
\hline 2 & Soil EC & 1 & 0 & 0 \\
\hline 3 & Organic Carbon & 28 & 22 & 78.57 \\
\hline \multicolumn{5}{|c|}{4 (A) Major Nutrients } \\
\hline & a. Nitrogen $(\mathrm{N})$ & 48 & 48 & 100 \\
\hline & b. Phosphorus & 45 & 42 & 93.33 \\
\hline & c. Potash & 10 & 8 & 80.00 \\
\hline & d. Sulphur & 28 & 24 & 85.71 \\
\hline \multicolumn{5}{|c|}{5 (B) Micro nutrients } \\
\hline & a. Zinc & 31 & 23 & 74.19 \\
\hline & b. Iron & 14 & 10 & 71.42 \\
\hline & c. Manganese & 21 & 20 & 95.23 \\
\hline & d. Boron & 8 & 5 & 62.50 \\
\hline & e. Copper & 6 & 2 & 33.33 \\
\hline
\end{tabular}

Table.3 Constraints among farmers about Soil Health Card

\begin{tabular}{|c|l|c|c|}
\hline S.No & \multicolumn{1}{|c|}{ Item } & Percent & RANK \\
\hline $\mathbf{1}$ & Difficulty in calculating fertilizer dose on the basis of nutrient status of soil & 46 & V \\
\hline $\mathbf{2}$ & Unavailability of micronutrient fertiliser in market & 54 & IV \\
\hline $\mathbf{3}$ & Sometimes adequate quantity of fertilisers not available & 42 & VI \\
\hline $\mathbf{4}$ & Prices of fertilisers are high & 68 & II \\
\hline $\mathbf{5}$ & Lack of knowledge about the importance of micronutrients & 70 & I \\
\hline $\mathbf{6}$ & Collection of soil sample was not done as per scientific equipment and technique & 22 & VIII \\
\hline $\mathbf{7}$ & Non-availability of NPK combination fertiliser & 32 & VII \\
\hline $\mathbf{8}$ & Non-availability of Organic Manure & 58 & III \\
\hline
\end{tabular}


Chowdary et al., (2016) also found that more than two-thirds (67 per cent) of the respondents had high level of satisfaction on SHC recommendations. These findings are consistent with the results found by Srivastava and Pandey (1999), Yadav et al., (2005), Pagaria (2011) and Patel and Chauhan (2012). To ensure the importance of the technology state government has always given their advisement in time interval to enhance balance and efficient use of fertilizers based on soil testing and soil health cards.

\section{Adoption among farmers according Soil health card based fertilizer application}

Data in the table 2 shows that maximum no. of respondents had high adoption percent related to nutrient deficiency found in major nutrients. 100\% Adoption percentage was found in application of Nitrogen whereas lowest adoption percentage i.e., 33.33 and $62.50 \%$ was found in application of copper and boron.

\section{Constraints among farmers about Soil health card}

The data illustrated above revealed that majority of farmers (70 percent) expressed difficulty in having knowledge about the importance of micronutrients. 68 percent of them expressed difficulty in the aspect that the prices of fertilizers are too high. While 58 percent farmers expressed their view on nonavailability of organic manure. Similar trend have been reported by Patel and Chauhan (2012) (Table 3).

It can be concluded from this study that majority of the farmers had medium knowledge level towards soil health card. Major constraints faced by the farmers in adoption according to soil health card were difficulty in having knowledge about the importance of micronutrients, the prices of fertilizers being too high and on nonavailability of organic manure. The farmers who were issued soil health card were comparatively more aware about various soil health card aspects like major nutrients $(\mathrm{N}, \mathrm{P}$ and $\mathrm{K}$ ), soil $\mathrm{pH}$ and Soil EC and micronutrients as compared to farmers without soil health card. Therefore it is suggested that the policy makers should make suitable programmes and train the farmers to use the soil health card to a maximum level.

\section{References}

Neufeld, J., Cramb, R., D. Catacutan, Z. Culasero-Arellano and K. Mariano, (2006). Farm level impacts of land care in Lantapan. Working Paper, No. 5. Philippines- Australia: Land Care Project.

Patel, R.C. (2000). A study on the consequences of adoption of watershed management technology by beneficiary farmers in watershed area of Kheda district of Gujarat State. Ph.D. Thesis, Sardarkrushi nagar, Dantiwada Agricultural University, SARDARKRUSHINAGAR, GUJARAT (India).

P.M. Bhatt, H. B. Patel and B. M. Patel (2010), A Study on Awareness About Soil Health Card, Guj. J. Extn. Edu. XX-XXI 2009-2010

Pagaria, P., (2011). Knowledge and attitude of small and marginal farmers towards soil testing. Journal of Advances in Developmental Research. 2(2): 171173.

Patel, J.K. and Chauhan, N.B. (2012). Attitude of farmers towards soil health card (SHC) programme. Asian J. Soil Sci., 7(1): 114-116.

Patel, G.G., Y.C. Lakum, Aakash Mishra and Bhatt, J.H. (2017). Awareness and Knowledge Regarding Soil Testing 
and Utility Perception of Soil Health Card. Int.J.Curr.Microbiol.App.Sci.

6(10): 329-334. doi https://doi.org/10.20546/ijcmas.2017.6 10.040

Srivastava, Y. C., and Pandey, A. P. (1999). Knowledge and attitude of small and marginal farmers towards soil testing.
Agricultural Extension Review. 11(6): 3-6.

Yadav, S. P. V., Raman, S.R. and Kumar, R. (2005). Knowledge and attitude farmers towards soil testing practices. Indian Research Journal of Extension Education. 6: 1-3.

\section{How to cite this article:}

Naruka, P.S., Shilpi Verma, C.P. Pachauri, S.S. Sarangdevot, Shilpi Kerketta, S.S. Bhadauria and Singh, J.P. 2018. Study on Knowledge, Adoption and Constraints Faced by Farmers about Soil Health Card based Fertilizer Application in Neemuch District, India. Int.J.Curr.Microbiol.App.Sci. 7(07): 1833-1837. doi: https://doi.org/10.20546/ijcmas.2018.707.217 